Discussion Paper No. 11-073

\title{
Resource Allocation Flexibility for Innovation Performance: \\ The Effects of Breadth, Uncertainty, and Selectiveness
}

Ronald Klingebiel and Christian Rammer

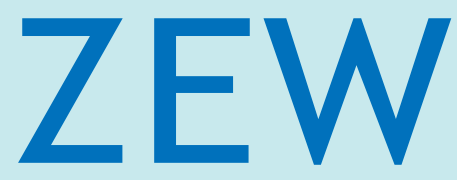

Zentrum für Europäische Wirtschaftsforschung $\mathrm{GmbH}$

Centre for European

Economic Research 
Discussion Paper No. 11-073

\title{
Resource Allocation Flexibility for Innovation Performance: The Effects of Breadth, Uncertainty, and Selectiveness
}

\author{
Ronald Klingebiel and Christian Rammer
}

Download this ZEW Discussion Paper from our ftp server:

http://ftp.zew.de/pub/zew-docs/dp/dp11073.pdf

Die Discussion Papers dienen einer möglichst schnellen Verbreitung von neueren Forschungsarbeiten des ZEW. Die Beiträge liegen in alleiniger Verantwortung der Autoren und stellen nicht notwendigerweise die Meinung des ZEW dar.

Discussion Papers are intended to make results of ZEW research promptly available to other economists in order to encourage discussion and suggestions for revisions. The authors are solely responsible for the contents which do not necessarily represent the opinion of the ZEW. 


\section{Non-technical Summary}

No matter how well resourced, innovation efforts are prone to failure. This paper investigates how the allocation of resources to product innovation projects allows firms to cope with this challenge. We assume that firms choose both the amount of financial resources devoted to innovation projects, and the number of projects. Based on data for almost 1,500 innovative firms from Germany, we test whether a policy of allocating resources to a broader range of innovation projects increases sales of new products. We analyze whether firms that allocate resources selectively by stopping projects with unfavorable prospects are more successful than nonselective firms. In addition, we also consider the degree of uncertainty in the product market as a further mediating variable of resource allocation efficiency.

We find that breadth in resource allocation increases innovation performance, more so than the amount of resources devoted to each project. The effect increases with novelty of the innovation output. We also show that the performance effect of breadth varies in different contexts. Firms can expect greater new product sales through breadth if they operate in uncertain market environments or if they allocate resources selectively.

The paper shows that firms' choice of resource allocation strategy impacts performance. We theorize how breadth can increase the chances of success, which is particularly important in uncertain markets, and how selectiveness can contain some of the disadvantages that come with breadth. A firm that follows a dual policy of resource allocation breadth and selectiveness is more flexible, dealing with innovation uncertainty more efficiently than its peers. 


\section{Das Wichtigste in Kürze}

Innovationsprojekte können immer wieder scheitern, unabhängig davon, wie viel Ressourcen Unternehmen für sie bereitgestellt haben. In diesem Beitrag wird untersucht, wie Unternehmen durch die Art der Allokation von finanziellen Mitteln auf Produktinnovationsprojekte den Innovationserfolg erhöhen können. Dabei wird angenommen, dass Unternehmen sowohl die Höhe der für Innovationsprojekte verfügbaren Mittel als auch die Zahl der unterschiedlichen Projekte festlegen. Auf der Grundlage von Informationen zu annähernd 1.500 innovativen Unternehmen in Deutschland untersuchen wir, ob eine Strategie, die verfügbaren Ressource auf eine größere Zahl von Projekten zu verteilen, zu einem höheren Umsatz mit neuen Produkten führt. Des Weiteren wird analysiert, ob eine selektive Mittelallokation, bei der wenig aussichtsreiche Projekte eingestellt und die Mittel auf die aussichtsreicheren Projekte konzentriert werden, zu höheren Innovationserfolgen führt. Dabei wird auch der Einfluss der Unsicherheit auf dem Absatzmarkt des Unternehmens berücksichtigt.

Die empirischen Ergebnisse zeigen, dass eine Strategie der „Breite“, d.h. der Verfolgung von vielen Innovationsprojekten, eher erfolgversprechend ist als die Strategie, weniger Projekte mit einem hohen Mittelumfang auszustatten. Der positive Effekt der „Breite“ ist besonders stark, wenn der Neuheitsgrad der Produktinnovationen hoch ist. Eine Strategie der „Breite“ empfiehlt sich insbesondere in Produktmärkten, die durch eine hohe Unsicherheit wie z.B. große, unvorhersehbare Schwankungen der Nachfrage gekennzeichnet sind. Eine selektive Vorgehensweise erhöht ebenfalls den Innovationserfolg.

Die Untersuchung belegt damit die wichtige Rolle der Art der Ressourcenallokation für den Erfolg von Produktinnovationsaktivitäten. Durch die Verfolgung viele unterschiedlicher Projekte können Unternehmen gerade unter unsicheren Marktbedingungen vermeiden, auf das falsche Pferd zu setzen. Die Vielfalt an Innovationsoptionen kompensiert dabei bei weitem den Umstand, dass das einzelne Projekt nur mit vergleichsweise geringen Mittel ausgestattet werden kann. Dabei scheint eine Kombination mit einer selektiven Innovationsstrategie, d.h. dem rechtzeitigen Einstellen von wenig aussichtsreichen Projekten, besondere zielführend zu sein. 


\title{
Resource Allocation Flexibility for
}

\section{Innovation Performance: The Effects of Breadth, Uncertainty, and Selectiveness}

\author{
Ronald Klingebiel $^{\mathrm{a}}$ and Christian Rammer ${ }^{\mathrm{b}}$
}

November 2011

\begin{abstract}
Our study shows empirically that the choice of resource allocation strategy affects innovation performance. A policy of allocating resources to a broader range of innovation projects increases sales of new products, especially if these are truly novel, i.e. new to the market. The effect of greater breadth appears to outweigh that of increased resource allocation per project. We find further indication that the performance effect of breadth increases with commercial uncertainty. It is also stronger for firms that allocate resources more selectively at later stages of the innovation process. Based on these results, we theorize that breadth increases performance as it spreads a firm's bets on unproven innovative endeavors, and more so when these endeavors are more uncertain. Limiting resource commitments through selectiveness contains breadth's disadvantages, a combination that provides flexibility in resource allocation.
\end{abstract}

Keywords: $\quad$ Innovation Performance, Resource Allocation, Uncertainty, Selectiveness, Innovation Management

JEL-Classification: L25, M21, O31, O32

Acknowledgement: This publication is the result of a project sponsored within the scope of the SEEK research programme which was carried out in cooperation with the University of Warwick and the Zentrum für Europäische Wirtschaftsforschung GmbH (ZEW) Mannheim, Germany.

a) Warwick Business School, Coventry CV4 7AL, UK - E-Mail: ronald.klingebiel@wbs.ac.uk (corresponding author)

b) Centre for European Economic Research (ZEW), L7 1, 68161 Mannheim, Germany - E-Mail: rammer@zew.de 


\section{INTRODUCTION}

In today's fast-moving markets, new products are more likely to fail than succeed (Loch and Kavadias, 2007). Nonetheless, competitive dynamics require firms to invest in innovation, even if, at the start of product innovation projects, little is known about their commercial viability (Brown and Eisenhardt, 1997; Hauser, Tellis, and Griffin, 2006). Allocating scarce resources to uncertain innovation endeavors is thus a daunting task for many organizational decision-makers.

In contrast to its managerial relevance, resource allocation strategy has scarcely featured in the research on innovation performance. Standard input-output models do not account for heterogeneity in resource allocation (cf. Crépon, Duguet, and Mairesse, 1998; Mairesse and Mohnen, 2002). The models' principal input factor tends to be innovation expenditure, which conceals variations in how these resources are allocated. Pouring more money into bad projects, however, does not necessarily increase performance.

In this paper, our aim is to test the effect of different resource allocation strategies on innovation performance. As resource allocation is a core activity for managers of innovations portfolios, this study adds to a growing body of literature that delineates how organizational differences in the strategic management of innovation impact performance (Cassiman and Veugelers, 2006; Grimpe and Kaiser, 2010; Laursen and Salter, 2006; Leiponen and Helfat, 2010, 2011; Li and Atuahene-Gima, 2001).

One strategy that managers may adopt to cope with the lack of information about the commercial viability of innovation projects is that of maintaining flexibility in resource allocation. Conceptual models of the new product development process have long advocated partial resource allocation that allows firms to invest broadly initially and more selectively over time (Ding and Eliashberg, 2002; Klein and Meckling, 1958; Nelson, 1961; Roberts and Weitzman, 1981). An initially broad allocation of portfolio resources to various innovation projects spreads risks, and subsequent selectiveness in providing follow-on funding focuses scarce resources on the most promising projects. Innovation funnels - broad exploration followed by selective commercialization - are thus thought to outperform less flexible resource allocation methods, especially in uncertain markets. 
Unfortunately, despite the plausibility of the theory, there is limited empirical evidence of the performance effect of flexible resource allocation. Empirical work in this area does not study innovation portfolios directly and often concentrates on breadth alone. Studies of product variety (Kekre and Srinivasan, 1990; Sorenson, 2000), for example, and research on breadth in firms' search efforts (Laursen and Salter, 2006; Leiponen and Helfat, 2010) have tended to endorse greater breadth. But findings originating from qualitative studies of the new product development process, which suggest benefits to funnel-style resource allocation (e.g. Cooper, Edgett, and Kleinschmidt, 2001; Wheelwright and Clark, 1992), remain untested. Recent contributions also cast doubt over the efficiency of stage-gate processes for resource allocation (Sethi and Iqbal, 2008). In an attempt to find anecdotal empirical evidence of both breadth and selectiveness, Ding and Eliashberg (2002) observe inconsistencies with their predicted funnel-model. The firms they observed tended to invest narrowly and avoid selecting out projects.

The need for comparative empirical research on the effect that resource allocation flexibility has on innovation performance motivates our study. We use data from the German section of the EU-wide Community Innovation Survey (CIS). CIS data are appropriate because three direct measures of firms' innovation performance are included: sales of new or improved products, sales of products that are new to the firm, and sales of products that are new to the market. We were fortunate in being able to append further questions to the questionnaire, capturing firms' strategies for allocating resources to projects in their innovation portfolio.

Results show that breadth has a significant positive direct impact on all three performance variables. The effect is strongest for new-to-market product sales, but it is context-dependent. In less uncertain environments, the breadth coefficient decreases and is less significant. Similarly, firms that do not allocate resources selectively do not see as strong a performance effect of breadth. Broad resource allocation is thus a more useful strategy for firms in uncertain markets and for those that allocate selectively. Interestingly, the performance impact of breadth is bigger and more significant than that of increased project investments.

Our theoretical contribution lies in the delineation of how heterogeneity in firms' resource allocation policies explains variance in performance outcomes. We theorize how resource allocation breadth leads to higher new product sales, and explain how this effect varies in the context of uncertainty. We also show that breadth is more advantageous when coupled with selectiveness. Spreading bets alone does not constitute flexibility, but coupled with selectiveness it does. 
In what follows, we discuss extant literature and develop three hypotheses. We then detail our empirical approach, present results, and address limitations. We conclude with a discussion of implications for theory.

\section{THEORY}

The success of a firm's suite of innovative activities is a function of the amount and quality of resources dedicated to the task. Variables consistently linked with innovation performance include innovation expenditure and human capital (Crépon et al., 1998; Mairesse and Mohnen, 2002). Given that only a fraction of innovation efforts are successful (Hauser et al., 2006), however, the performance relationship is more complicated. Commercial uncertainty shortens the period within which managers, no matter how intelligent or well resourced they are, can confidently predict key determinants of innovation success, such as future customer preferences, technological standards, or competitive landscapes. Often, the time-to-market for new product developments exceeds this period (Griffin, 1997; Hauser et al., 2006). Therefore, when firms allocate scarce resources to chosen innovative endeavors, they run the risk of misjudging the prospects of success. Projects that initially look promising may ultimately fail, and projects that initially seem unconvincing may ultimately succeed.

Firms' innovation activities are often organized in portfolios of projects (Brown and Eisenhardt, 1995; Hauser et al., 2006; Shane and Ulrich, 2004). For portfolio managers, the generation and selection of project variants is a prime concern (Loch and Kavadias, 2007). It is thus peculiar that the performance effect of heterogeneity in firms' strategies to allocate resources to innovation projects has received conceptual attention (Ding and Eliashberg, 2002; Roberts and Weitzman, 1981) but limited empirical research. It is our objective to address this gap by testing for the impact of resource allocation breadth and selectiveness.

Many firms operate an innovation process during which resource allocation decision-making is revisited at several points (Schmidt, Sarangee, and Montoya, 2009). These decision points allow for control over project resourcing, requests for which typically increase as projects move from one phase of the innovation process to the next. The decisions made at such points determine the breadth and selectiveness of resource allocation. By breadth, we mean the parallelization of innovation efforts, indicating a strategy of funding the start of several different innovation projects. Selectiveness refers to resource allocation decisions at later stages of 
development projects, indicating a strategy of deliberate discrimination between projects that deserve further resource allocation and those that do not. Prior research suggests that firms display substantial variation in the degree to which they allocate innovation resources broadly and selectively (Cooper et al., 2001; Griffin, 1997; Hauser et al., 2006).

In what follows, we develop three hypotheses about the relationship between firms' resource allocation strategy and innovation performance.

\section{Resource Allocation Breadth}

One informative setting in which breadth has been researched empirically is that of product variety (for a review see Lancaster, 1990). Scholars articulate a positive relationship between variety and performance. Kekre and Srinavasan (1990) show that a broader set of new products increases the chances of fit between product characteristics and consumer preferences. As a result, greater product variety is associated with firms' persistence in an industry (Sorenson, 2000). One would expect a similar rationale at work during new product development, where resources are spread across a number of projects, covering various aspects of potential future customer preferences. The assumption is that a few extraordinary innovation successes outweigh the inevitable costs of producing many mediocre innovations. For example, Ding and Eliashberg (2002) report that Sony had pursued between 20 and 30 development projects in the area of videotape recorder technology, in order to increase chances of success in one of them.

This performance logic is also employed with regard to breadth of search and objectives. More sources of innovation and a broader search pattern lead to better informed new product decisions (Katila and Ahuja, 2002; Laursen and Salter, 2006; Leiponen and Helfat, 2010). The greater the number of different objectives associated with product innovation activities, the greater the predicted performance (Leiponen and Helfat, 2010).

The above works suggest breadth increases the odds of success, and we hypothesize for innovation management:

H1) Spreading resources broadly, i.e. across a greater number of development projects, increases product innovation performance. 


\section{Breadth and Uncertainty}

Scholars have also stressed disadvantages of breadth, proposing a u-shape relationship with performance as well as generally detrimental effects in particular contexts. For example, greater breadth in search may reduce managerial attention to a project, thus dcreasing output quality (Barnett, 2008; Laursen and Salter, 2006), although not all studies could replicate this countervailing effect (Leiponen and Helfat, 2010) or found it negligible (Kekre and Srinivasan, 1990). Breadth in product innovation portfolios can also starve individual projects of sufficient resourcing, increase managerial complexity, reduce incentives, and hamper strategic focus and thrust generally (Ghemawat and Costa, 1993; Klingebiel, 2010; Sull, 2003).

In view of these potential downsides, breadth might be more useful in some circumstances than in others. Uncertainty provides a context against which parallel search has been particularly emphasized (Klein and Meckling, 1958; Marschak and Nelson, 1962; Nelson, 1961). With decreasing managerial confidence in the performance outcomes of innovation projects, pursuing several avenues in parallel becomes more important to improve the odds of success. In a context of uncertainty, the positive aspects of breadth are thus more likely to outweigh its negative ones. For example, greater task uncertainty in public problem solution contests has been shown to increase the positive effect of parallel search relative to its detriments such as participant disincentives (Boudreau, Lacetera, and Lakhani, 2011). The logic of uncertainty offsetting potentially negative effects of breadth has also been invoked, though not empirically addressed, in the literature of product variety (e.g. Lancaster, 1990; Sorenson, 2000) and search efforts (Laursen and Salter, 2006; Leiponen and Helfat, 2010).

It is thus timely to test for the conditioning effect of uncertainty on the relationship between resource allocation breadth in product innovation and performance. We suggest that market environments where managers have a reduced ability to predict new product success provide the context for a greater performance benefit of breadth. We hypothesize:

H2) The effect of resource allocation breadth (H1) is greater in the context of uncertainty. 


\section{Breadth and Selectiveness}

The second context in which breadth stands to be more beneficial is one where resources are not fully committed and can be withdrawn from candidate products that seem less promising over time.

The advantages of breadth derive from increasing the odds of including successful candidate products during initial project selection-when little is known about projects' commercial viability and exploration is relatively affordable. But this advantage diminishes over time. At later stages of development, project resource requirements increase, and managers can typically construct a more informed opinion about a project's commercial viability (Loch and Kavadias, 2007). Breadth is thus comparatively less useful and more expensive to maintain for projects in later stages of development. If a firm's broad innovation project lineup translates directly into a broad new product portfolio, it benefits from a higher likelihood of offering blockbuster products but also suffers from offering more lackluster products.

The conjecture is that firms which allocate later-stage development resources selectively generate greater innovation performance. Selectiveness ensures that fewer lackluster products reach the market. Resources originally marked for the development of projects with deteriorating prospects can be used by more promising candidate projects, thus increasing the quality of the final output from these projects. The concept is one of efficient failure (McGrath, 1999). A new product development process with broad allocation of small initial funds, and selective allocation of more substantial funds as commercial uncertainty resolves, is expected to lead to greater performance than a process that allocates funds to a fixed number of projects (Ding and Eliashberg, 2002; Roberts and Weitzman, 1981).

Taking advantage of experimenting broadly, while containing the disadvantages of breadth through selectiveness, is reflected in the concept of flexibility (Sanchez, 1993), which enables probing and learning without committing the organization to launching potentially disappointing products (Brown and Eisenhardt, 1997; McGrath, 1999; Sitkin, 1992). Spreading bets broadly and committing selectively is thus a more advantageous resource allocation strategy than breadth alone. In this paper, we aim to test whether broad resource allocation in the context of selectiveness generates greater performance than broad allocation in a context where firms do not select out. We hypothesize: 
H3) The effect of resource allocation breadth (H1) is greater in the context of selectiveness.

\section{DATA AND METHODS}

\section{Sample}

The data are drawn from the 2009 Mannheim Innovation Panel, which constitutes the German part of the European Community Innovation Survey (CIS). The German CIS is sponsored by the Federal Ministry of Education and Research and conducted in cooperation with the Institute for Applied Social Science Research, one of the largest market and poll research institutes in the country. CIS data have been used in countless economic articles and, more recently, attracted attention from the management community (Cassiman and Veugelers, 2006; Grimpe and Kaiser, 2010; Laursen and Salter, 2006; Leiponen and Helfat, 2010). The statistical agency of the European Commission, Eurostat, coordinates the survey instrument and, in close coordination with EU member states, produces a harmonized questionnaire applied in each country participating in the CIS exercise. Basic definitions and the survey methodology rest on the OECD’s document “The Measurement of Scientific and Technological Activities, Proposed Guidelines for Collecting and Interpreting Technological Innovation Data,” also known as the Oslo Manual, which contains guidelines for collecting and interpreting innovation data (OECD \& Eurostat, 2005). Reliability and validity of CIS data are supported by extensive piloting and pretesting.

Questionnaire data are processed using semi-automated methods of data input. Each response is subject to comprehensive quality control, including a consistency check with responses by the same firm in earlier survey waves. Since the German CIS is conducted annually, and most firms participate regularly, survey respondents are familiar with the main concepts and definition of the survey and can rely on established accounting and reporting tools to provide the various data asked for in the questionnaire.

Targeted at executive officers in charge of innovation, CIS's main strength is the provision of direct measures of firm success in commercializing innovations, across a broad range of industries. These measures provide a powerful complement to traditional innovation measures of patenting activity. In the CIS data, a commercialized product innovation is defined as a novel or 
significantly improved product or service introduced to the market. These are categorized as either new-to-market, new to a firm's product portfolio, or improvements to the existing range of products. The 2009 survey wave contains information on innovation for the period 2006-2008. In addition to the normal set of items, the 2009 survey also contained specific questions about breadth and selectiveness, as described in the section on measures below.

The gross target sample of the 2009 wave consists of 35,197 enterprises. The sample is stratified by sector (56 sectors at the two-digit level of NACE rev. 2.0), size class (eight classes according to the number of employees) and region (West Germany and East Germany). The sample firms were contacted via mail survey, with an option to respond online. Firms that did not respond within six weeks of being mailed the questionnaire received a telephone reminder and were sent another copy of the questionnaire. After another six weeks, a final reminder followed. The process rendered 5,388 firms classified as neutral losses: they could either not be contacted or were confirmed to have ceased operation. Out of the corrected gross sample of 29,807 enterprises, 7,061 usable responses were received. The response rate of 25 percent is slightly below that of Cassiman and Veugelers (2006) and Laursen and Salter (2006) but of the usual magnitude for voluntary mail surveys in Germany (Grimpe and Kaiser, 2010), particularly when considering the substantial length of the questionnaire. Sector and size composition of the net sample does not differ significantly from the gross sample, indicating that the net sample is representative in terms of the sector and size distribution of the German firm population.

In order to control for a possible selection bias between responding and non-responding firms in terms of their innovation status, an extensive non-response survey was conducted, surveying 4,829 enterprises by telephone. This survey revealed a higher share of innovating firms among the non-responding firms (63.1 percent) compared with the net sample of responding firms (54.3 percent). This information is used to re-calculate weights for economic projections and policy analysis but is of limited concern for our study (Janz et al., 2001; Peters, 2008).

For this paper, we use only a sub-sample of survey responses. We exclude 3,017 firms that did not conduct any product innovation activity during the observation period. Some 399 firms have fewer than 10 employees, the standard threshold for CIS analysis (Laursen and Salter, 2006; Leiponen and Helfat, 2010). We also drop 41 nascent firms that were founded only during the observation period. A total of 1,082 observations show missing values in at least one dimension of interest, resulting in a final data set of 1,495 firms. 


\section{Measures}

Dependent Variables: Performance in product innovation is conceptualized as the extent to which a firm generates commercially successful new products, evidenced through revenue from new product sales. To account for potential differences in the novelty of the new products generated, we adopt the customary categories: (a) sales originating from new-to-market products, (b) sales from new-to-the-firm products, and (c) sales from all new products and improved products. On average, 6 percent of our sample firms' sales are attributed to new-to-market products (a), 10 percent to new-to-firm products (b), and 25 percent to new and improved products (c). The operationalization and distribution of these variables are in line with prior CIS work (Laursen and Salter, 2006; Rammer, Czarnitzki, and Spielkamp, 2009).

All three measures contain absolute values. They have the advantage of providing greater construct validity than ratios (e.g. new product sales/overall sales); a performance increase in absolute terms can be more directly interpreted as being related to a firm's innovation activities than an increase in relative terms. An increase in a ratio can be due to a firm selling more successful new products as well to the firm selling less successful legacy products. Absolute figures for new product sales avoid this phenomenological conflation. In addition, ratios lead to extreme values for smaller firms, a problem that does not occur with absolute values (Mairesse and Mohnen, 2010).

Independent Variables: We introduce a new variable for resource allocation breadth. As suggested in the literature on new product development (Ding and Eliashberg, 2002; Loch and Kavadias, 2007; Roberts and Weitzman, 1981), we asked CIS firms to report the number of innovation projects pursued during 2006-2008. Answers were then normalized with regard to firm size. This measure of breadth thus reflects the range of innovative efforts across which firms spread a standardized unit of innovation resources.

Orthogonal to the breadth of the project portfolio is the amount of resources allocated per project. If a firm increases its overall innovation budget, it can afford either more projects or more resources per project. We operationalize project resourcing by dividing a firm's overall innovation expenditure by the number of projects it pursued. By controlling for the level of project resourcing, it becomes possible to identify the separate performance effect of allocating resources to a broader range of projects. 
As regards uncertainty, our theoretical interest is specifically in the extent to which managers can rely on available information to gauge the commercial prospects of future new products. For this purpose we operationalize uncertainty as the volatility of year-to-year industry sales (threedigit level) over the period 2002-2007 (five years prior to the year for which innovation output is measured). These data are drawn from the value added tax statistics of the Federal Statistical Office of Germany. As a widely used, established measure (e.g. Agle et al., 2006; Beckman, Haunschild, and Damon, 2004) it allows us to investigate the effect of resource allocation breadth in two types of environments: a relatively unstable one where managers struggle to predict future new product sales, and a stable one where this is comparatively easier.

Selectiveness refers to a firm's policy of allocating resources discriminately as projects move through the innovation process. For our analysis, the objective is not to prescribe the optimal share of projects that should be pruned, chiefly because this varies within each firm and period. Instead, our goal is to capture whether firms apply any selection pressure at all. This is relatively easy to detect: selective firms differ from non-selective firms in that their project portfolio breadth diminishes over time (Adner, 2007; Ding and Eliashberg, 2002; Guler, 2007). The survey thus asked whether or not a firm discontinued some of the innovation projects it pursued during 2006-2008. The responses provide us with two categories for the selectiveness variable: a firm that completes all its projects is not selective; a firm that completes only a subset is selective. In our sample, 40 percent of firms were selective.

Control Variables: Our model contains controls that are frequently included in models explaining innovation performance (Crépon et al., 1998; Grimpe and Kaiser, 2010; Leiponen and Helfat, 2010; Mairesse and Mohnen, 2002). We use firm sales to account for size, because larger firms generate greater new product sales in absolute terms, all else being equal. To control for the quality of input to the innovation process, we measure the proportion of employees with university degree. We further control for the degree to which firms carried out research and development on a continuous basis (yes/no). Whether firms were engaged in process innovation (yes/no) is also included as this is a valuable organizational activity that may influence our model focused on product innovations. One could also imagine variation in innovation performance that is due to firms' experience, which is why we drew firm age information from the national registry. In addition, we control for variation in performance that may be due to the focal firm belonging to a mother group of companies. Finally, we include a set of 22 industry dummy variables representing groups of two-digit level NACE sectors. This is to control for potential 
industry-level variations in firms' capacity to generate innovation performance. Tables 1 and 2 show descriptive statistics for our main model variables.

Insert Tables 1 and 2 here - Descriptives \& Correlations

\section{Estimation}

Our data are censored, making Tobit analysis the estimation method of choice. We follow established designs for innovation performance models based on CIS (Grimpe and Kaiser, 2010; Laursen and Salter, 2006; Leiponen and Helfat, 2010). We depart from this only in that we decompose the usual innovation expenditure variable into portfolio breadth and project expenditure. Hypotheses II and III are tested through comparative split-sample analysis (Carpenter and Westphal, 2001; Cassiman and Veugelers, 2006; Terwiesch and Loch, 1999). As we hypothesize uncertainty and selectiveness to be contextual variables, we divide our sample into respective subsets. We thus dichotomize our measure of uncertainty, with those firms falling below the 40 percentile classified as in relatively stable market environments and those falling above the 60 percentile classified as in relatively unstable environments. We did the same for selectiveness, splitting respondents into a group that did not discontinue any projects and one that did.

Table 1 shows descriptive statistics for the split samples. Two distributions are noteworthy. The first is that firms in low-uncertainty environments invest less in innovation than their peers. This is consistent with the logic that greater uncertainty requires a greater effort to achieve comparable returns. The second is that selective firms tend to be bigger, and thus have more projects (but not greater breadth, as breadth is sales-normalized), than non-selective firms. This is probably due to our operationalization of selectiveness; firms with bigger portfolios are more likely to discontinue at least one of their projects. We address this limitation and present robustness checks in the section below the results.

All models use logarithmic transformations of the dependent variable. Innovation performance is strongly skewed in all three categories and, accordingly, the pattern observed in the empirical distribution is more fairly represented by lognormal distributions (for a detailed discussion, see 
Laursen and Salter, 2006). Similarly, the controls for firm size and innovation expenditure are also imputed in lognormal form.

We assume a partial lag between resource allocation and innovation performance by relating new product sales in 2008 to independent variables measured for the period 2006-2008. While there appears to be no consensus on the lag structure of innovation input and output (cf. Mairesse and Mohnen, 2010), we ensured that our operationalization is in line with that of prior CIS studies (Cassiman and Veugelers, 2006; Grimpe and Kaiser, 2010; Laursen and Salter, 2006). In addition, we compared the results of two base models (cf. Mairesse and Mohnen, 2010), one including 2009 values and one including 2010 values. The 2010 model, with greater lag, explained 15 percent less variance than the 2009 model.

\section{Results}

Table 3 reports estimated marginal effects on the three dependent variables in full-sample models. Using the recommended design (Mairesse and Mohnen, 2010), our Reference Model shows significance for size, innovation expenditure, continuous R\&D, and process innovation. These observations reflect are consistent with recent CIS studies (Grimpe and Kaiser, 2010; Laursen and Salter, 2006; Leiponen and Helfat, 2010). From new product sales, through new-tofirm product sales, to new-to-market product sales, the quality of resources becomes more significant. The coefficient of innovation expenditure and that of continuous R\&D also increase with greater novelty of products sold. These changes across dependent variables are theoretically plausible as they indicate the greater challenges of generating truly novel product innovations. McFadden $\mathrm{R}^{2}$ values for the reference models are consistent with prior CIS work (Laursen and Salter, 2006).

The next results reported refer to the Base Model, which tests for the direct effect of resource allocation breadth. Here, innovation expenditure is entered on a per-project basis to separate its effect from breadth. The results for the control variables are in line with the reference model. The effect of breadth on innovation performance is positive significant, increasingly so with greater novelty of products sold. This effect is consistent across all further models and supports H1. An interesting side observation in the Base Model is that the effect of innovation expenditure per project is insignificant and switches its sign with greater novelty of products sold. This picture does not change as the two contextual variables are added to the model (Full Model). Coefficients for the control variables, project breadth and expenditure hardly change. While we treat this 
empirical observation with caution, it suggests that the effect of overall innovation expenditure is mainly driven by the breadth of the project portfolio rather than by the magnitude of project investments.

Insert Table 3 here - Full Sample Models

The Full Model shows no direct influence of uncertainty and selectiveness on innovation success, which is consistent with our theoretical argument that it is a contextual factor. Selectiveness does appear to also have a direct influence that is significant. We turn to the contextual influence of uncertainty and selectiveness in Tables 4 and 5. Table 4 displays the results of the split-sample models used to test for the effect of breadth in the context of low and high uncertainty. The effect of breadth is positive significant in both contexts, but the confidence level and the magnitude of the coefficient are greater in the high-uncertainty context.

To test whether the variation in coefficient values is statistically significant we computed the Z-score (Clogg, Petkova, and Haritou, 1995). For new product sales, new-to-firm product sales, and new-to-market product sales, the Z-score is significant at the 1 percent and 5 percent level for new product sales and new-to-market product sales, respectively. We further examined whether the assumption of two separate regression models is correct, using the Chow test methodology (Chow, 1960). Results confirm this assumption at the 0.1 percent-level for all three categories. It suggests that, across the two sub-samples, firms vary significantly in their capacity to generate innovation performance. In sum, the results of the uncertainty-split models support $\mathrm{H} 2$

In the split-sample models, as in the previous models, the coefficient of breadth increases with novelty of product sales. As previously observed, the effect of project expenditure is weak. The control variables show effects similar to the prior models, with the slight exception of age, the effect of which becomes positive in high-uncertainty environments, suggesting benefits to experience (low significance level). 
Insert Table 4 here - Split-Sample Models: Uncertainty

Table 5 shows the results of the split-sample models used to test for the effect of breadth under the context of selectiveness and non-selectiveness. Both selective and non-selective firms see a significant positive performance effect of breadth, but the confidence level and the magnitude of the coefficient are greater for selective firms. The Z-Scores are significant at the .1 percent-level for all performance categories, lending strong support to H3. Chow tests render significance of .1 percent, 13 percent, and 10 percent for new product sales, new-to-firm sales, and new-to-market sales, respectively. It suggests that selective and non-selective firms vary significantly in their capacity to generate innovation performance.

The effects of the control variables in the split-sample models of Table 5 are broadly consistent with those of the full-sample models. The quality of resources becomes more significant with greater novelty of product sales. Whether or not a firm is part of a larger group of firms appears to matter more for selective firms, suggesting that not being able to make completely independent decisions is a disadvantage for selective firms. Innovation expenditure per project shows only a weak influence on performance.

Insert Table 5 here - Split-Sample Models: Selectiveness

\section{Robustness, Sensitivity, and Limitations}

Interpreting changes in absolute values for the dependent variables in our models provides greater validity than focusing on ratios, but it comes with the disadvantage of having to include size as a control which then explains a substantial portion of the overall variance. To check for multicollinearity, we inspected the variance inflation factors of uncensored models. For the main independent variables, variance inflation factors do not exceed 1.7, which alleviates concerns of multicollinearity. To further check for model distortions through size, we reviewed semi-partial correlations. For the input variables reported as significant in the models above, semi-partial correlation values range from 0.05 to 0.22 , while those of size range between 0.19 and 0.34 . 
These figures confirm that the independent variables explain non-trivial portions of the overall model variance (Budescu, 1993).

We then ran our model designs again, this time with ratios as dependent variables. Dividing new product sales by overall sales reduces the influence of size as a control variable. Results of the ratio models were consistent with those reported above, suggesting that hypothesized effects of breadth are independent of size (Kleinknecht, Van Montfort, and Brouwer, 2002). The effect is strong enough to show even though ratios as dependent variables are influenced by more causal factors than absolute values.

Bigger firms with bigger project portfolios are also more likely than smaller firms to select out at least one of their projects. We thus examined whether the way we constructed the selectiveness subsamples is robust to perturbations. Instead of by general selectiveness, we dichotomized the sample by whether firms pruned their portfolio to an extent above or below a threshold, e.g. $20 \%$. This is a theoretically inferior operationalization and also causes greater imbalance in subsample sizes. But for this measure too, the result of breadth's greater performance for selective firms holds. By contrast, a comparison of samples split into larger and smaller firms does not show significant differences in the effect of breadth. We then also checked if our dichotomization of low and high uncertainty is robust to perturbations. Alternative sample splits at the median (which reduces discriminant validity) and at 30/70 percentiles (which reduces the subsample sizes) rendered model results consistent with those reported above.

The research design is relatively robust against reverse causality. There is no obvious reason to suspect higher-performing firms of allocating resources more broadly. Nevertheless, we ran a reverse regression model, for a subset of firms for which pre-observation period performance data are available. We find no statistical significance for the effect of innovation performance on subsequent portfolio breadth.

Our work suffers from the usual abstractions and assumptions in econometric models and would benefit from future research. Interesting firm-level differences include the quality of ideas that are fed into the innovation process, an aspect for which we cannot currently control. Industry-level differences in innovation routines, the nature of innovation projects, or returns to innovation efforts are currently accounted for only through a series of industry dummies. Future research may be able to measure some of these differences more directly. Conversely, singleindustry contexts may offer the opportunity to study in more detail the causal chain between 
portfolio resource allocation breadth and performance. Such studies may be able to identify various sources of innovation uncertainty and trace the reasoning for project discontinuations, both of which could moderate the relationships we propose.

\section{DISCUSSION}

Increasing the quality and quantity of innovation resources is not a sufficient answer to the challenge posed by commercial uncertainty inherent in most of today's innovation projects. A firm's performance in innovation also depends on how it allocates the available resources. By showing this empirically, this research deepens understandings of the determinants of product innovation performance. Our model results indicate that, when firms' overall innovation expenditure is separated into resource allocation breadth and project resourcing, breadth significantly impacts performance, independent of resourcing. This effect is stronger for firms in high-uncertainty environments and for those that allocate resources selectively in later stages of the product innovation process. As discussed below, these findings have implications for theory of organizational resource allocation and innovation management.

\section{Resource Allocation Breadth and Innovation Performance}

We find evidence of a positive relationship between innovation performance and the allocation of resources across a broader range of innovation projects. Because managers have to commit resources before the performance implications of these commitments are fully understood, scholars have argued conceptually that greater breadth increases a firm's chance of success (Ding and Eliashberg, 2002; Klein and Meckling, 1958; Marschak and Nelson, 1962; Nelson, 1961; Roberts and Weitzman, 1981). We add to these previous conceptualizations the first empirical support for the conjecture that greater resource allocation breadth increases innovation performance.

The effect is positive significant for all three categories of innovative output: new product sales, new-to-firm product sales, or new-to-market product sales. The effect is greatest for the latter: the more novel the new product output, the greater the performance contribution of resource allocation breadth. Our interpretation is that greater novelty means that managers have fewer sources of information about a new product's commercial viability to rely on when making initial resource allocation decisions. Therefore, greater novelty increases the benefit that firms 
gain from a broad resources allocation strategy, improving their chances of satisfying future customer preferences that are not fully known in the early stages of new product development.

In our models, breadth also proves a more significant predictor of a firm's capacity to come up with a new-to-market product than the magnitude of resource investment, a key variable in economic models (Crépon et al., 1998; Mairesse and Mohnen, 2002). When separating overall innovation resourcing into the breadth and intensity of resource allocation, the results indicate that spreading resources across a greater number of projects is more important than increasing project resourcing. An innovation manager might thus be advised to err on the side of spreading resources too thinly, rather than concentrating substantial resources on an insufficient number of new product candidates. Our finding suggests that innovation is about getting the right new products at least as much as it is about getting new products right.

The paper extends the literature on the strategic management of innovation by delineating resource allocation breadth as a predictor of innovation performance. But the underlying mechanism may apply more widely. Breadth spreads a firm's commercial bets and makes it more likely that at least some investments will turn out to be successful, a mechanism that could also explain prior findings in adjacent fields, namely in the areas of product variety (Bordley, 2003; Lancaster, 1990; Sorenson, 2000) and search breadth (Laursen and Salter, 2006; Leiponen and Helfat, 2010).

\section{Effect Heterogeneity: Uncertainty}

While we observe a generally positive relationship between breadth and performance, we also show that this effect is not uniform across firms. There is a significant difference in the extent to which firms in less and more uncertain environments benefit from greater breadth. This difference exists within all three performance categories.

Breadth increases a firm's odds of success, but the degree to which this is the case is contingent on uncertainty. Firms in less uncertain markets can rely more on historic information than firms in more uncertain markets. The former are thus less likely than the latter to misjudge the commercial prospects of an innovation project in the early stages of development. As a result, firms operating in less uncertain markets have less to gain from breadth than firms in more uncertain markets. 
The difference in effect between the two contexts of low and high uncertainty also suggests that breadth may carry disadvantages. Research indicates that these could include lack of strategic focus and diseconomies of scale (Ghemawat and Costa, 1993; Klingebiel, 2010). Another downside of breadth is that project managers' motivation may decrease if more of them compete for innovation resources (Garcia and Tor, 2009). Although we are unable to trace specifically the ways in which breadth could be detrimental, our results indicate that any potential disadvantages of breadth are proportionately more offset by the advantages in a context of greater uncertainty. If uncertainty is low, the probability of investing in a doomed innovation project is smaller and the benefits of commitment to a focused path of action may outweigh the benefits of breadth. This interpretation is consistent with a recent study of innovation tournaments where the motivational disadvantages of higher numbers of participants were less problematic when uncertainty was high (Boudreau et al., 2011).

The theoretical conjecture thus is that a strategy of broad resource allocation is a more worthwhile pursuit in some circumstances than others. By identifying uncertainty as a key contingent of the performance effect of breadth, the paper provides some explanation for why prior studies adjacent fields have suggested that the effect of product variety, for example, is not unequivocally positive (Bordley, 2003; Sorenson, 2000). It may also help explain the curvilinearity posited in studies on the breadth of firms' search activities (Laursen and Salter, 2006).

\section{Effect Heterogeneity: Selectiveness}

We also find a significant difference in the extent to which selective and non-selective firms benefit from greater breadth. The effect of breadth on all three categories of new product sales is greater if firms exert selectiveness in resource allocation over time. In addition, the direct effect of selectiveness is also positive significant.

The direct effect indicates that pruning projects from an innovation portfolio increases innovation performance. Our interpretation is that managers, reacting to information that emerges during new product development, select out projects with declining commercial propensity. As a result, selective firms launch fewer lackluster products. They can also reallocate resources to more promising projects in the portfolio. This focuses innovation resources and stands to benefit the output quality and development speed of these projects, which we ultimately see reflected in higher performance. 
As regards the conditioning effect of selectiveness on the performance effect of breadth, we theorize that pruning the project portfolio over time mitigates the disadvantages of greater resource allocation breadth (while maintaining its advantages). Selectiveness makes pursuing a broad resource allocation strategy more economical, due to two dynamics: resource needs are lower for early-stage development projects than for later-stage projects, and commercial viability is less clear for early-stage projects than for later-stage projects (cf. Hauser et al., 2006; Loch and Kavadias, 2007). It thus makes sense to allocate resources broadly in the early stages of the development process, while being more selective in later stages. It allows for greater exploration when projects' commercial viability is still unclear, and for more focus when commercial viability is better established. High performers in innovation thus combine resource allocation breadth with selectiveness.

We therefore contribute an explanation for performance differentials that are rooted in firms' strategies for allocating resources within innovation portfolios. This insight connects with broader conceptualizations of strategic responsiveness. Where uncertainty cannot be reduced exante, efficient adaptation mechanisms are thought to influence performance, be they conceptualized as low-cost probes (Brown and Eisenhardt, 1997), learning through failure (McGrath, 1999; Sitkin, 1992), or flexibility (Sanchez, 1995). Innovation portfolio management provides an exemplary setting where competitive pressure requires resource allocation before outcomes are fully understood. Resource allocation breadth, coupled with selectiveness, provides a mechanism for coping with this challenge - one that constitutes responsiveness and distinguishes high performers.

These findings resonate with initial conceptualizations (Klein and Meckling, 1958; Marschak and Nelson, 1962; Nelson, 1961) and qualitative research on funnel-style innovation management (Cooper et al., 2001; Wheelwright and Clark, 1992). With breadth and selectiveness being key features of resource allocation funnels, our paper suggests that firms employing funnels outperform those that do not. At the same time, our findings run counter to a recent study suggesting disadvantages to stage-gate funnels (Sethi and Iqbal, 2008). Interestingly, we also find that breadth and selectiveness are particularly important for innovation performance resulting from new-to-market products. This provides an alternative view to the notion that funnels, based on a (potentially inert) set of decision criteria, discriminate against radical innovations and thus hurt performance in this area (Hauser et al., 2006). In fact, our results suggest that the likelihood 
of any new idea becoming a successful new-to-market innovation may be so low that breadth plus selectiveness are necessary mechanisms to generate more successful novel products.

\section{CONCLUSION}

No matter how well resourced, innovation efforts are prone to failure. We thus set out to investigate how the allocation of resources to product innovation projects allows firms to cope with this challenge. We find that breadth in resource allocation increases innovation performance, more so than resource allocation intensity. The effect increases with novelty of the innovation output. We also show that the performance effect of breadth varies in different contexts. Firms can expect greater new product sales through breadth if they operate in uncertain market environments or if they allocate resources selectively. It also appears that increasing innovation expenditure per project has a weaker link to performance than increasing resource allocation breadth.

We contribute to explaining innovation performance differentials. Firms' choice of resource allocation strategy impacts performance. We theorize how breadth can increase the chances of success, which is particularly important in uncertain markets, and how selectiveness can contain some of the disadvantages that come with breadth. A firm that follows a dual policy of resource allocation breadth and selectiveness is more flexible, dealing with innovation uncertainty more efficiently than its peers.

\section{REFERENCES}

Adner R. 2007. Real options and resource reallocation processes. Advances in Strategic Management 24(1): 363-372.

Agle B, Nagarajan N, Sonnenfeld J, Srinivasan D. 2006. Does ceo charisma matter? An empirical analysis of the relationships among organizational performance, environmental uncertainty, and top management team perceptions of ceo charisma. Academy of Management Journal 49(1): 161-174.

Barnett M. 2008. An attention-based view of real options reasoning. Academy of Management Review 33(3): 606-628.

Beckman CM, Haunschild PR, Damon JP. 2004. Friends or strangers? Firm-specific uncertainty, market uncertainty, and network partner selection. Organization Science 15(3): 259-275. 
Bordley R. 2003. Determining the appropriate depth and breadth of a firm's product portfolio. Journal of Marketing Research 40(1): 39-53.

Boudreau KJ, Lacetera N, Lakhani KR. 2011. Incentives and problem uncertainty in innovation contests: An empirical analysis. Management Science 57(5): 843-863.

Brown S, Eisenhardt K. 1995. Product development: Past research, present findings, and future directions. Academy of Management Review 20(2): 343-378.

Brown SL, Eisenhardt KM. 1997. The art of continuous change: Linking complexity theory and time-paced evolution in relentlessly shifting organizations. Administrative Science Quarterly 42(1): 1-34.

Budescu DV. 1993. Dominance analysis: A new approach to the problem of relative importance of predictors in multiple regression. Psychological Bulletin 114(3): 542-551.

Carpenter M, Westphal J. 2001. The strategic context of external network ties: Examining the impact of director appointments on board involvement in strategic decision making. Academy of Management Journal 44(4): 639-660.

Cassiman B, Veugelers R. 2006. In search of complementarity in innovation strategy: Internal r\&d and external knowledge acquisition. Management Science 52(1): 68.

Chow G. 1960. Tests of equality between sets of coefficients in two linear regressions. Econometrica 28(July): 591-605.

Clogg CC, Petkova E, Haritou A. 1995. Statistical methods for comparing regression coefficients between models. American Journal of Sociology 100(5): 1261-1293.

Cooper R, Edgett S, Kleinschmidt E. 2001. Portfolio management for new products. Addison Wesley: Reading, MA.

Crépon B, Duguet E, Mairesse J. 1998. Research investment, innovation and productivity: An econometric analysis. Economics of Innovation and New Technology 7(2): 115-158.

Ding M, Eliashberg J. 2002. Structuring the new product development pipeline. Management Science 48(3): 343-363.

Garcia SM, Tor A. 2009. The n effect: More competitors, less competition. Psychological Science 20(7): 871-877.

Ghemawat P, Costa JERI. 1993. The organizational tension between static and dynamic efficiency. Strategic Management Journal 14(1): 59-73.

Griffin A. 1997. Pdma research on new product development practices: Updating trends and benchmarking best practices. Journal of Product Innovation Management 14(6): 429-458. 
Grimpe C, Kaiser U. 2010. Balancing internal and external knowledge acquisition: The gains and pains from r\&d outsourcing. Journal of Management Studies 47(8): 1483-1509.

Guler I. 2007. Throwing good money after bad? Political and institutional influences on sequential decision making in the venture capital industry. Administrative Science Quarterly 52(2): 248-285.

Hauser J, Tellis G, Griffin A. 2006. Research on innovation: A review and agenda for marketing science. Marketing Science 25(6): 687-717.

Janz N, Ebling G, Gottschalk S, Niggemann H. 2001. The mannheim innovation panels (mip and mip-s) of the centre for european economic research (zew). Schmollers Jahrbuch 121(1): 123-129.

Katila R, Ahuja G. 2002. Something old, something new: A longitudinal study of search behavior and new product introduction. Academy of Management Journal 45(6): 1183-1194.

Kekre S, Srinivasan K. 1990. Broader product line: A necessity to achieve success? Management Science 36(10): 1216-1231.

Klein B, Meckling W. 1958. Application of operations research to development decisions. Operations Research 6(3): 352-363.

Kleinknecht A, Van Montfort K, Brouwer E. 2002. The non-trivial choice between innovation indicators. Economics of Innovation and New Technology 11(2): 109-121.

Klingebiel R. 2010. Deploying strategic initiatives: Further consideration of the flexibilitystability balance. In Strategic reconfigurations: Building dynamics capabilities in rapid innovation-based industries. Wall S, Zimmermann C, Klingebiel R, Lange D (eds.), Edward Elgar: Cheltenham.

Lancaster K. 1990. The economics of product variety: A survey. Marketing Science 9(3): 189206.

Laursen K, Salter A. 2006. Open for innovation: The role of openness in explaining innovation performance among uk manufacturing firms. Strategic Management Journal 27(2): 131150.

Leiponen A, Helfat C. 2010. Innovation objectives, knowledge sources, and the benefits of breadth. Strategic Management Journal 31(2): 224-236.

Leiponen A, Helfat C. 2011. Location, decentralization, and knowledge sources for innovation. Organization Science 22(3): 641-658.

Li H, Atuahene-Gima K. 2001. Product innovation strategy and the performance of new technology ventures in china. Academy of Management Journal 44(6): 1123-1134. 
Loch C, Kavadias S. 2007. Managing new product development: An evolutionary framework. In Handbook of new product development management. Loch C, Kavadias S (eds.), Butterworth Heinemann: Oxford.

Mairesse J, Mohnen P. 2002. Accounting for innovation and measuring innovativeness: An illustrative framework and an application. American Economic Review 92(2): 226-230.

Mairesse J, Mohnen P. 2010. Using innovations surveys for econometric analysis.

Marschak T, Nelson R. 1962. Flexibility, uncertainty, and economic theory. Metroeconomica 14(1): 42-58.

McGrath R. 1999. Falling forward: Real options reasoning and entrepreneurial failure. Academy of Management Review 24(1): 13-30.

Nelson R. 1961. Uncertainty, learning, and the economics of parallel research and development efforts. Review of Economics and Statistics 43(4): 351-364.

Peters B. 2008. Innovation and firm performance: An empirical investigation for german firms. Physica: New York.

Rammer C, Czarnitzki D, Spielkamp A. 2009. Innovation success of non-r\&d-performers: Substituting technology by management in smes. Small Business Economics 33(1): 35-58.

Roberts K, Weitzman M. 1981. Funding criteria for research, development, and exploration projects. Econometrica: 1261-1288.

Sanchez R. 1993. Strategic flexibility, firm organization, and managerial work in dynamic markets: A strategic options perspective. Advances in Strategic Management 9(1): 251291.

Sanchez R. 1995. Strategic flexibility in product competition. Strategic Management Journal 16(S1): 135-159.

Schmidt J, Sarangee K, Montoya M. 2009. Exploring new product development project review practices. Journal of Product Innovation Management 26(5): 520-535.

Sethi R, Iqbal Z. 2008. Stage-gate controls, learning failure, and adverse effect on novel new products. Journal of Marketing 72(1): 118-134.

Shane S, Ulrich K. 2004. Technological innovation, product development, and entrepreneurship in management science. Management Science 50(2): 133-144.

Sitkin S. 1992. Learning through failure: The strategy of small losses. Research in Organizational Behavior 14(2): 231-231. 
Sorenson O. 2000. Letting the market work for you: An evolutionary perspective on product strategy. Strategic Management Journal 21(5): 577-592.

Sull D. 2003. Management by commitments. Harvard Business Review 81(6): 82-91.

Terwiesch C, Loch CH. 1999. Measuring the effectiveness of overlapping development activities. Management Science 45(4): 455-465.

Wheelwright SC, Clark KB. 1992. Revolutionizing product development: Quantum leaps in speed, efficiency, and quality. Free Press: New York. 
TABLES

TABLE 1: SPLIT SAMPLE DESCRIPTIVES

\begin{tabular}{|c|c|c|c|c|c|c|}
\hline Variable & & Observations & Mean & $\begin{array}{r}\text { Standard } \\
\text { Deviation }\end{array}$ & Minimum & Maximum \\
\hline \multirow[t]{5}{*}{ New Product Sales (2008 €m) } & All & 1,484 & 2.036 & 13.477 & 0 & 363.580 \\
\hline & Low uncertainty & 611 & 1.462 & 9.453 & 0 & 206.119 \\
\hline & High uncertainty & 593 & 1.722 & 7.855 & 0 & 123.280 \\
\hline & No Selectiveness & 950 & 0.950 & 5.444 & 0 & 123.280 \\
\hline & Selectiveness & 534 & 3.963 & 21.116 & 0 & 363.580 \\
\hline \multirow[t]{5}{*}{ New-to-Firm Product Sales (2008 €m) } & All & 1,484 & 0.683 & 5.310 & 0 & 151.126 \\
\hline & Low uncertainty & 611 & 0.486 & 4.214 & 0 & 96.997 \\
\hline & High uncertainty & 593 & 0.511 & 2.337 & 0 & 33.567 \\
\hline & No Selectiveness & 950 & 0.227 & 1.033 & 0 & 17.388 \\
\hline & Selectiveness & 534 & 1.492 & 8.682 & 0 & 151.126 \\
\hline \multirow[t]{5}{*}{ New-to-Market Product Sales (2008 €m) } & All & 1,484 & 0.536 & 5.107 & 0 & 151.126 \\
\hline & Low uncertainty & 611 & 0.374 & 4.140 & 0 & 96.997 \\
\hline & High uncertainty & 593 & 0.366 & 1.991 & 0 & 28.560 \\
\hline & No Selectiveness & 950 & 0.143 & 0.697 & 0 & 10.787 \\
\hline & Selectiveness & 534 & 1.234 & 8.413 & 0 & 151.126 \\
\hline \multirow[t]{5}{*}{ Firm Size (avg 2006-2008, sales in €m) } & All & 1,484 & 156.590 & 781.561 & 0.206 & 17012.520 \\
\hline & Low uncertainty & 611 & 82.470 & 324.257 & 0.264 & 4281.346 \\
\hline & High uncertainty & 593 & 132.799 & 444.331 & 0.206 & 4446.395 \\
\hline & No Selectiveness & 950 & 76.451 & 301.541 & 0.206 & 4281.346 \\
\hline & Selectiveness & 534 & 299.160 & 1227.138 & 0.370 & 17012.520 \\
\hline \multirow[t]{5}{*}{ Resource Quality (2008, \% staff w/ degree) } & All & 1,484 & 0.233 & 0.240 & 0 & 1 \\
\hline & Low uncertainty & 611 & 0.199 & 0.220 & 0 & 1 \\
\hline & High uncertainty & 593 & 0.267 & 0.252 & 0 & 1 \\
\hline & No Selectiveness & 950 & 0.237 & 0.246 & 0 & 1 \\
\hline & Selectiveness & 534 & 0.228 & 0.232 & 0 & 1 \\
\hline \multirow[t]{5}{*}{ Process Innovation (2006-2008, yes/no) } & All & 1,484 & 0.611 & 0.487 & 0 & 1 \\
\hline & Low uncertainty & 611 & 0.616 & 0.487 & 0 & 1 \\
\hline & High uncertainty & 593 & 0.601 & 0.490 & 0 & 1 \\
\hline & No Selectiveness & 950 & 0.582 & 0.493 & 0 & 1 \\
\hline & Selectiveness & 534 & 0.662 & 0.473 & 0 & 1 \\
\hline \multirow[t]{5}{*}{ Continuous R\&D (2006-2008, yes/no) } & All & 1,484 & 0.566 & 0.496 & 0 & 1 \\
\hline & Low uncertainty & 611 & 0.484 & 0.500 & 0 & 1 \\
\hline & High uncertainty & 593 & 0.616 & 0.486 & 0 & 1 \\
\hline & No Selectiveness & 950 & 0.501 & 0.500 & 0 & 1 \\
\hline & Selectiveness & 534 & 0.682 & 0.466 & 0 & 1 \\
\hline \multirow[t]{5}{*}{ Firm Age (years, in 2008) } & All & 1,484 & 33.526 & 40.316 & 4 & 509 \\
\hline & Low uncertainty & 611 & 33.760 & 40.028 & 4 & 467 \\
\hline & High uncertainty & 593 & 31.813 & 40.051 & 4 & 509 \\
\hline & No Selectiveness & 950 & 30.711 & 37.924 & 4 & 467 \\
\hline & Selectiveness & 534 & 38.519 & 43.835 & 4 & 509 \\
\hline \multirow[t]{5}{*}{ Part of Group (2008, yes/no) } & All & 1,484 & 0.431 & 0.495 & 0 & 1 \\
\hline & Low uncertainty & 611 & 0.413 & 0.492 & 0 & 1 \\
\hline & High uncertainty & 593 & 0.424 & 0.494 & 0 & 1 \\
\hline & No Selectiveness & 950 & 0.354 & 0.478 & 0 & 1 \\
\hline & Selectiveness & 534 & 0.569 & 0.496 & 0 & 1 \\
\hline \multirow{5}{*}{$\begin{array}{l}\text { Innovation Expenditure (avg 2006-2008, } \\
\text { for portfolio, \% of sales) }\end{array}$} & All & 1,484 & 0.075 & 0.444 & 0.001 & 0.879 \\
\hline & Low uncertainty & 611 & 0.044 & 0.080 & 0.001 & 0.663 \\
\hline & High uncertainty & 593 & 0.104 & 0.490 & 0.001 & 0.879 \\
\hline & No Selectiveness & 950 & 0.072 & 0.407 & 0.001 & 0.727 \\
\hline & Selectiveness & 534 & 0.079 & 0.504 & 0.001 & 0.879 \\
\hline Innovation Expenditure (avg 2006-2008, & All & 1,484 & 0.817 & 2.960 & 0.001 & 58.016 \\
\hline$€ \mathrm{~m} /$ project) & Low uncertainty & 611 & 0.619 & 1.918 & 0.001 & 23.400 \\
\hline & High uncertainty & 593 & 1.040 & 3.957 & 0.001 & 58.016 \\
\hline & No Selectiveness & 950 & 0.793 & 2.598 & 0.001 & 37.500 \\
\hline & Selectiveness & 534 & 0.859 & 3.514 & 0.001 & 58.016 \\
\hline Resource Allocation Breadth (2006-2008, & All & 1,484 & 15.932 & 53.000 & 1 & 800 \\
\hline \# of projects) & Low uncertainty & 611 & 13.291 & 46.736 & 1 & 720 \\
\hline & High uncertainty & 593 & 15.001 & 44.476 & 1 & 800 \\
\hline & No Selectiveness & 950 & 10.333 & 46.330 & 1 & 800 \\
\hline & Selectiveness & 534 & 25.862 & 61.931 & 1 & 800 \\
\hline Commercial Uncertainty (2002-2007, industry & All & 1,484 & 9.271 & 13.057 & 1.552 & 91.187 \\
\hline sales volatility, 3-digit level) & Low uncertainty & 611 & 3.905 & 1.045 & 1.552 & 5.442 \\
\hline & High uncertainty & 593 & 16.143 & 18.520 & 7.471 & 91.187 \\
\hline & No Selectiveness & 950 & 8.693 & 12.012 & 1.552 & 91.187 \\
\hline & Selectiveness & 534 & 10.297 & 14.686 & 1.552 & 91.187 \\
\hline Selectiveness (2006-2008, yes/no) & All & 1,484 & 0.361 & 0.480 & 0 & 1 \\
\hline & Low uncertainty & 611 & 0.330 & 0.471 & 0 & 1 \\
\hline & High uncertainty & 593 & 0.367 & 0.481 & 0 & 1 \\
\hline & No Selectiveness & 950 & 0 & 0 & 0 & 0 \\
\hline & Selectiveness & 534 & 1 & 0 & 1 & 1 \\
\hline
\end{tabular}


TABLE 2: CORRELATIONS

ตำ

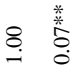

త్ర

$\stackrel{i}{8} \stackrel{0}{0}$

ฮ

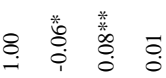

ఠ

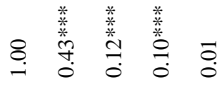

बำ

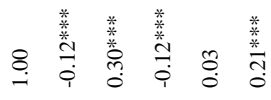

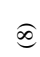

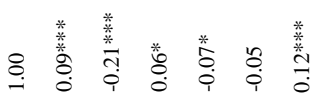

E

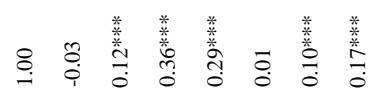

Q

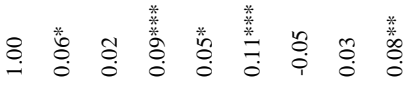

ธำ

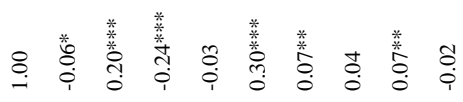

Ð

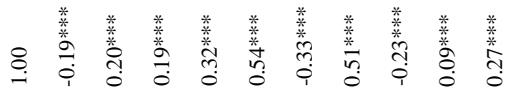

중

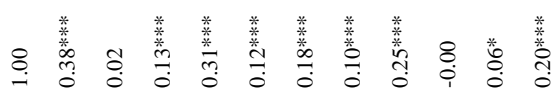

త

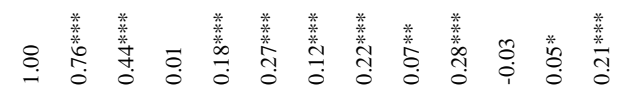

$\Xi$

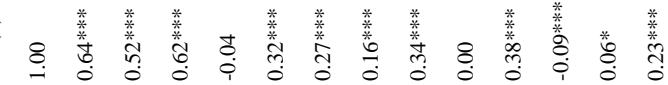

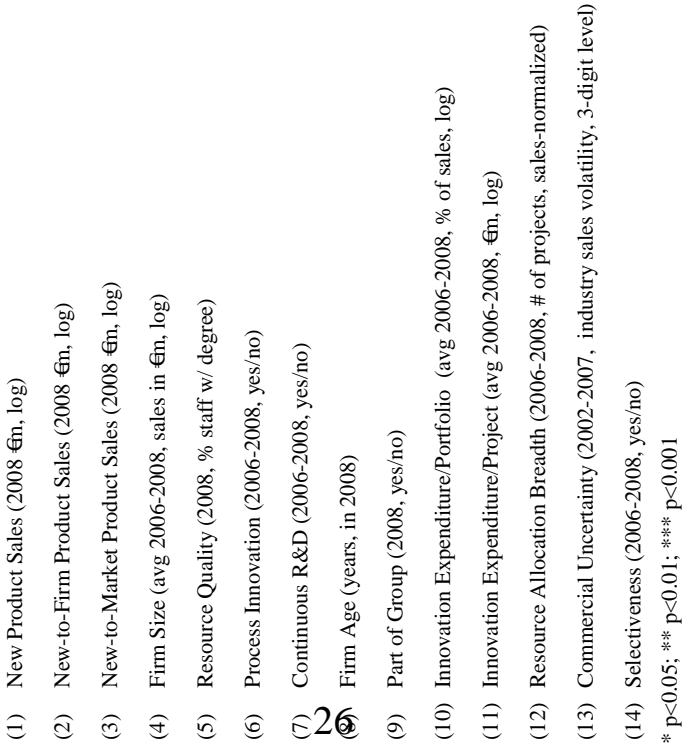


TABLE 3: FUlL SAMPLE MODELS

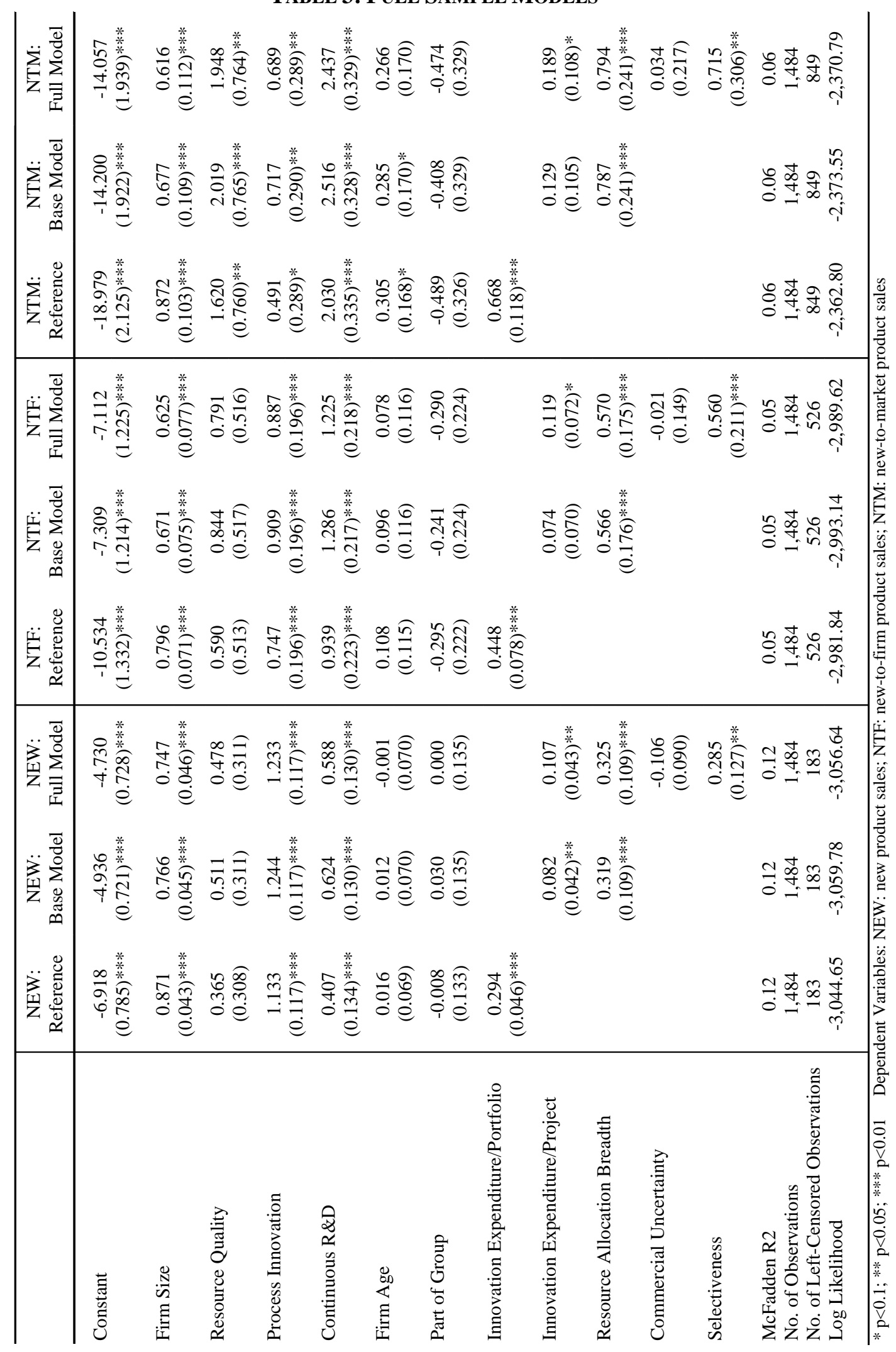


TABLE 4: SPLIT-SAMPLE MODELS: UNCERTAINTY

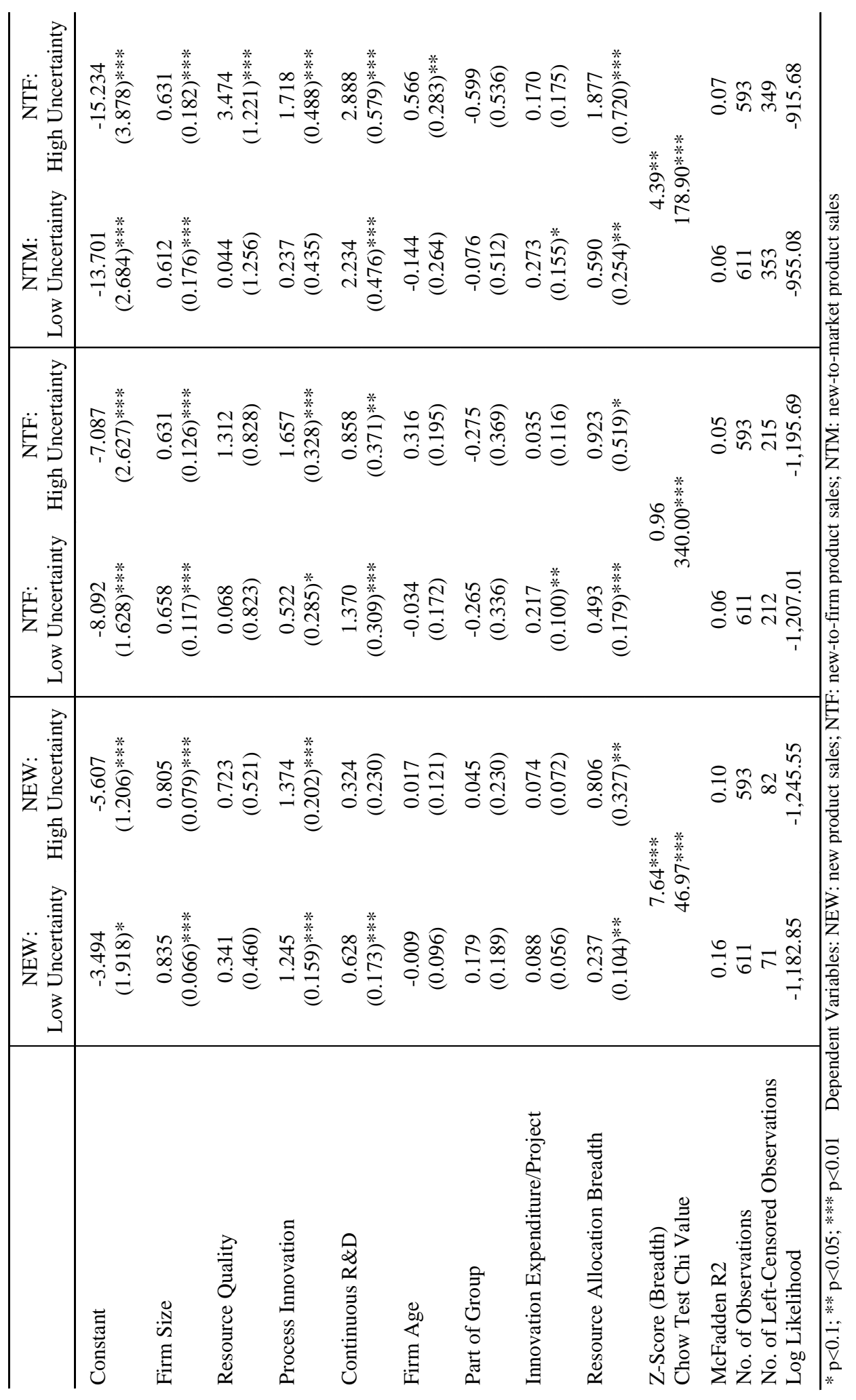


TABLE 5: SPliT-SAMPLE MODELS: SELECTIVENESS

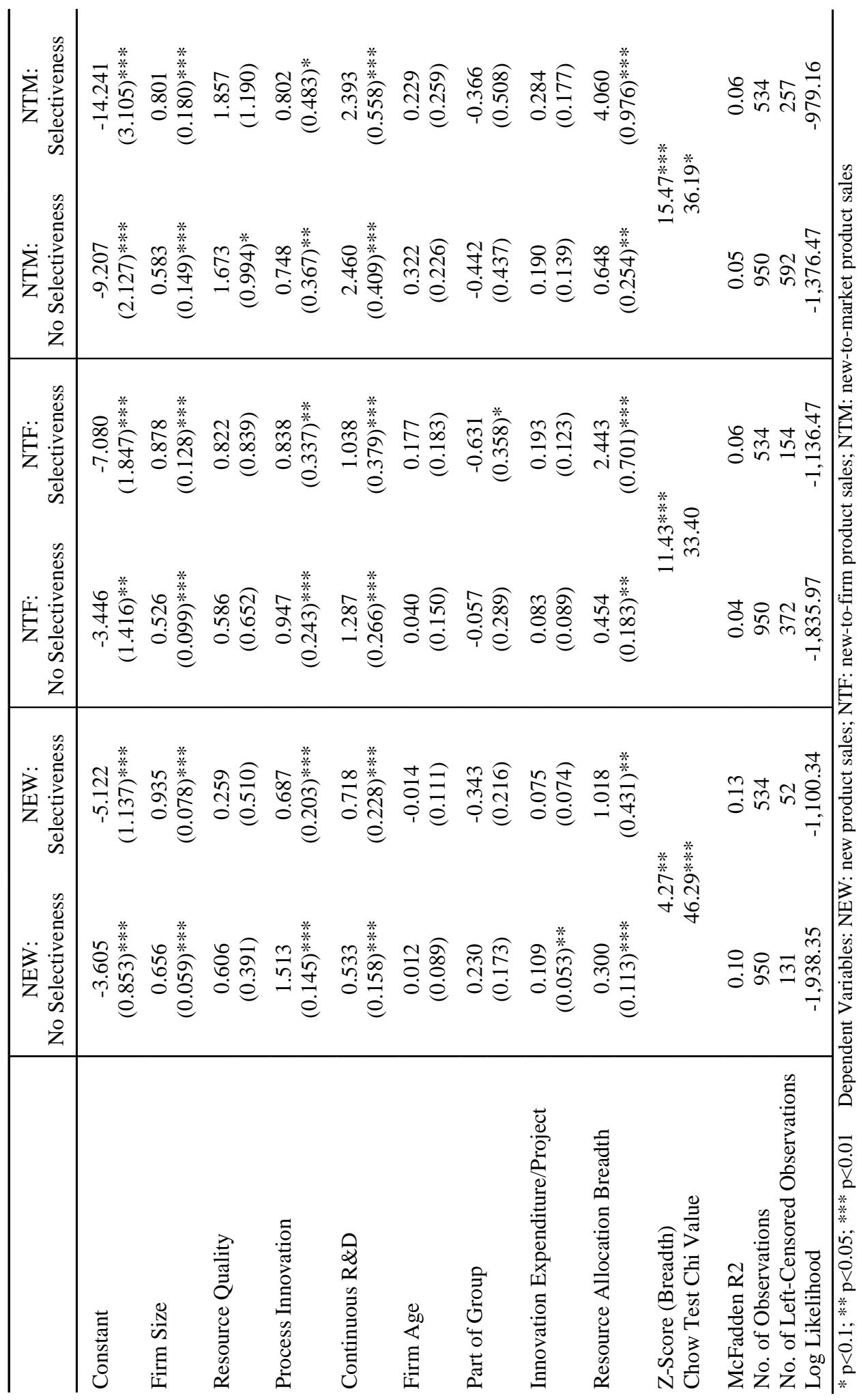

